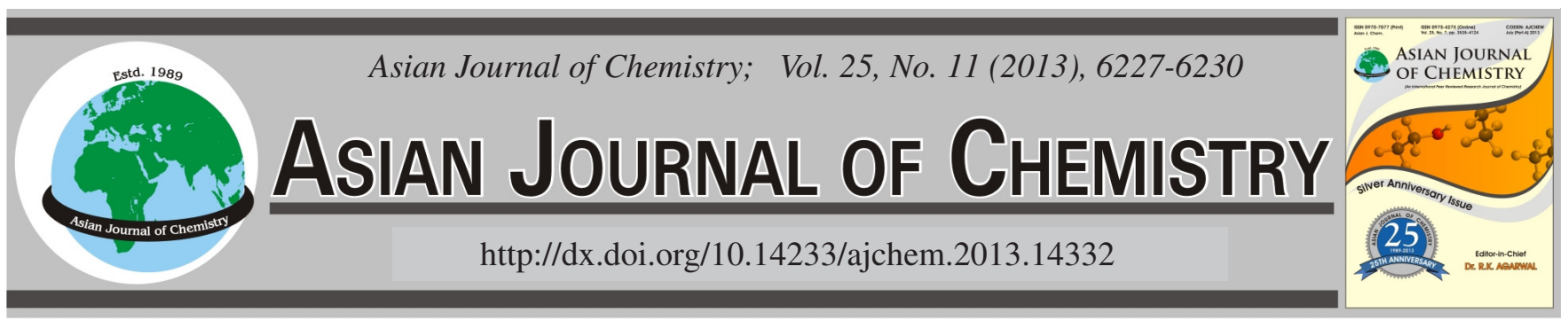

\title{
Study of Damping Properties of Glass Fibers Reinforced Scrap Rubber Composites Prepared by Simple Mixing
}

\author{
Mingunn Li*, Yongwen Xu, YuAncheng Qin and Yanping Sun
}

Department of Environmental and Chemical Engineering, Nanchang Hangkong University, Nanchang 330063, P.R. China

*Corresponding author: E-mail: limingjun1958@gmail.com

(Received: 19 July 2012;

Accepted: 2 May 2013)

AJC-13442

\begin{abstract}
A simple and efficient method was developed to prepare glass fibers reinforced scrap rubber composites by simple mixing. The effect of the concentration and length (L)/diameter (D) on the damping and mechanical properties was studied. The optimization values of the concentration and L/D are determined to be $30 \mathrm{~g}$ and 4:1, respectively. The interface topography was also studied by SEM to implore the microstructure and damping mechanism of the composites.

Key Words: Scrap rubber composites, Damping, Glass fibers.
\end{abstract}

\section{INTRODUCTION}

As automobiles are the fastest growing mode of transportation throughout the world, scrap tyre is becoming a serious source of environmental problem because they are not biodegradable. A number of approaches have been suggested to recycle the waste tires, such as combustion for fuel, landfills, incorporating in the pavements, pyrolysis to recover different chemicals $^{1}$. However, some of the approaches have been proven uneconomical and inefficient with respect to processing the large quantity of waste tire generated every year. One of the methods for utilization of these materials is their use in concrete and other building products. To shred and ground the waste tire to scrap rubber powder is one of economical and promising approaches. The research and development of the scrap rubber powder and plastics composites have very important significances ${ }^{2}$. So, numerous researchers focused on how to make use of scrap rubber ${ }^{3}$. However, the scrap rubber powder materials can not be used directly because of their low elastic modulus and poor creep resistance and have to be combined with other materials to form high performance composites.

In recent years, cellulose fibers have become an important class of reinforcing materials ${ }^{4,5}$. Glass fibers is reported to have good reinforcing effect along with natural fibers like sisal, jute, hemp, etc. ${ }^{6,7}$ Many studies have been reported on the dynamic mechanical behaviour of hybrid composites of natural fibers and glass fiber ${ }^{8-10}$. Thermoplastic natural rubber was recently reinforced by the short carbon and kenaf fiber hybrid systems ${ }^{11}$. Dynamic mechanical properties of short glass/ bamboo fiber reinforced polyester composites are dependent on the volume fraction of the fiber and percentage of glass fiber replaced by bamboo fiber ${ }^{12}$. The storage modulus, loss modulus and $\tan \delta$ of the untreated hybrid composite were found better than those of the treated hybrid composites.

High vibration levels are usually undesirable, which often generate excessive noise and lead to mechanical fatigue damage. Viscoelastic polymers as damping materials have attracted considerable attention both in academia and industry due to their outstanding properties for reducing vibration and noise $^{13,14}$. Rubber is a common and cheap material in controlling noise and vibration due to its high damping property. However, its mechanical property is so low that it has to be used with other rigid materials in engineering application, especially for scrap rubber powder ${ }^{15}$. In order to get a structural and functional material with high performences, researchers have made great efforts to study fiber-reinforced composites ${ }^{16-21}$. Most of these work indicated that the damping property of these composites would decrease acutely while their mechanical properties increase. Here, one kind of composite made of glass fibers and scrap rubber powder was designed and prepared to get excellent properties of both damping and mechanical properties.

\section{EXPERIMENTAL}

The matrix was scrap rubber and the reinforcements were glass fibers. The scrap rubber powder was purchased from Jinli Chemical Company (Henan, China) and the glass fibers were purchased from Sinopharm Chemical Reagent Company (Shanghai, China). The ratios of length(L)/diameter(D) of glass fibers were $2: 1,3: 1,4: 1,6: 1,8: 1$ and 10:1. 
The glass fibers reinforced scrap rubber composites were prepared in open rubber refining mill (Hualong Rubber Machinery company, Qingdao, China). Different masses and ratios of length and diameter of glass fibers were milled with scrap rubber powder to produce uniform thickness (about 2 $\mathrm{mm}$ ) composite film. Then, the film was cut into sheets with the length of $170 \mathrm{~mm}$ and the width of $100 \mathrm{~mm}$. At last, the test samples were put into the mould for vulcanization molding process.

The mechanical properties were carried out in WDW-50D computer controlled electronic universal test machine. The tensile strength (TS, Mpa) was calculated from the following formula:

$$
\mathrm{TS}=\frac{\mathrm{Fm}}{\mathrm{Wt}}
$$

here, Fm is the recorded maxium strength $(\mathrm{N}), \mathrm{W}$ is the width $(\mathrm{mm})$ of the test composite film sample and $\mathrm{t}$ is the thickness $(\mathrm{mm})$ of the test composite film sample.

The Elongation at break $\left(\mathrm{E}_{\mathrm{b}}, \%\right)$ at room temperature was determined from the following formula:

$$
\mathrm{E}_{\mathrm{b}}=\frac{100\left(\mathrm{~L}_{\mathrm{b}}-\mathrm{L}_{0}\right.}{\mathrm{L}_{0}}
$$

here, $L_{b}(\mathrm{~mm})$ is gauge length of the test composite film sample at break and $\mathrm{L}_{0}(\mathrm{~mm})$ is the initial gauge length of the test composite film sample at break.

The damping properties were determined from dynamic mechanical properties analysis (DMA). Because rubber is viscoelastic polymer, the stress $(\sigma)$ can be expressed by the following relationship:

$$
\sigma=\left|\mathrm{E}^{*}\right| \cdot|\varepsilon| \sin (\omega \mathrm{t}+\delta)
$$

where $\mathrm{E}^{*}$ is the compound modulus, $\varepsilon$ is strain amplitude, $\omega$ is angular frequencyand, $\mathrm{t}$ is time and $\delta$ is phasing degree between stress and strain. So $\tan \delta$ is called dissipation factor to express the damping property of the materials.

\section{RESULTS AND DISCUSSION}

To study the effect of the concentration of glass fiber on the damping properties of the composites, different masses of glass fibers and $100 \mathrm{~g}$ scrap rubber powder were used to prepared the test samples. Fig. 1 shows the damping property of glass fibers reinforced scrap rubber composites under different concentration of glass fibers. As shown in Fig. 1, the damping properties of all the composites increase with the increase of the frequency. When the frequency increased to $200 \mathrm{~Hz}$, the dissipation factor became saturation and would not increase any more. The initial scrap rubber without glass fibers shows very poor damping property and the dissipation factor is just 0.165 . After mixing glass fibers as the reinforced materials, the dissipation factor increased gradually. When the mass of glass fibers increased to $30 \mathrm{~g}$ (the mass ratio of glass fiber and scrap rubber is $3: 10$ ), the dissipation factor is reaching to the maximum of 0.314 , which is about twice of that of the initial scrap rubber materials.

Fig. 2 shows the mechanical properties of glass fibers reinforced scrap rubber composites under different concentration of glass fibers. As shown in Fig. 2, the tensile strength

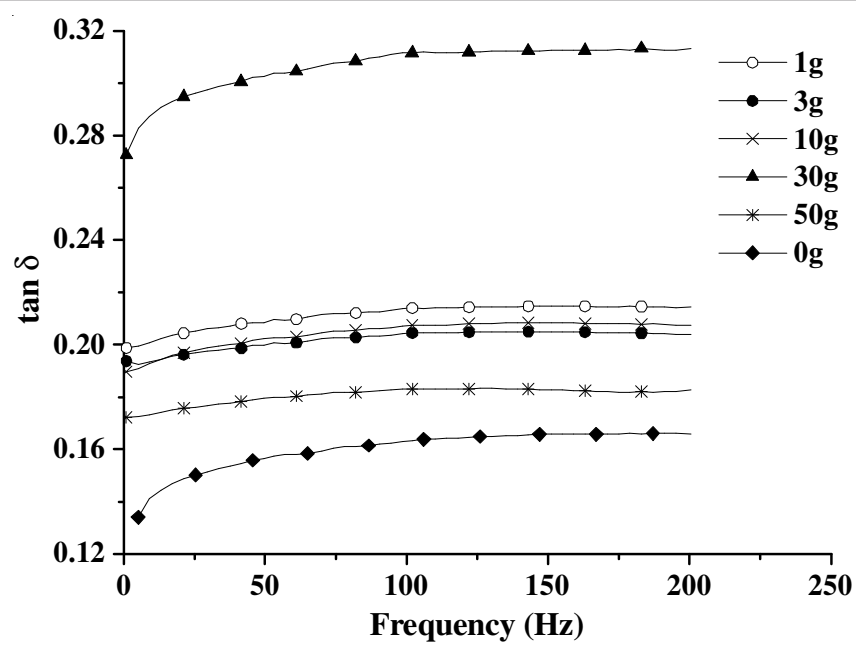

Fig. 1. Damping properties of glass fibers reinforced scrap rubber composites under different concentration of glass fibers. (length (L)/diameter (D) of glass fibers is 4:1)

first increased with the increase of the concentration of glass fibers. When the concentration of glass fibers reached to $5 \mathrm{~g}$, the tensile strength is achieved the maximum value of 2.72 Mpa. If the concentration of glass fibers was increased any more, the tensile strength would decrease rapidly. At the concentration of $30 \mathrm{~g}$, the curve appeared an inflexion, which implied the tensile strength had a minimum of 2.11 Mpa and again increased with the increase of the concentration of glass fibers after $30 \mathrm{~g}$. For the elongation at the break, as shown in Fig. 2, the values decreased along with the concentration of glass fibers. The elongation first decreased slowly less than the concentration of $30 \mathrm{~g}$. And then it would decrease rapidly with increase of the concentration of glass fibers. To sum up, the concentration of $30 \mathrm{~g}$ glass fibers was the optimization value for keeping both damping and mechanical properties.

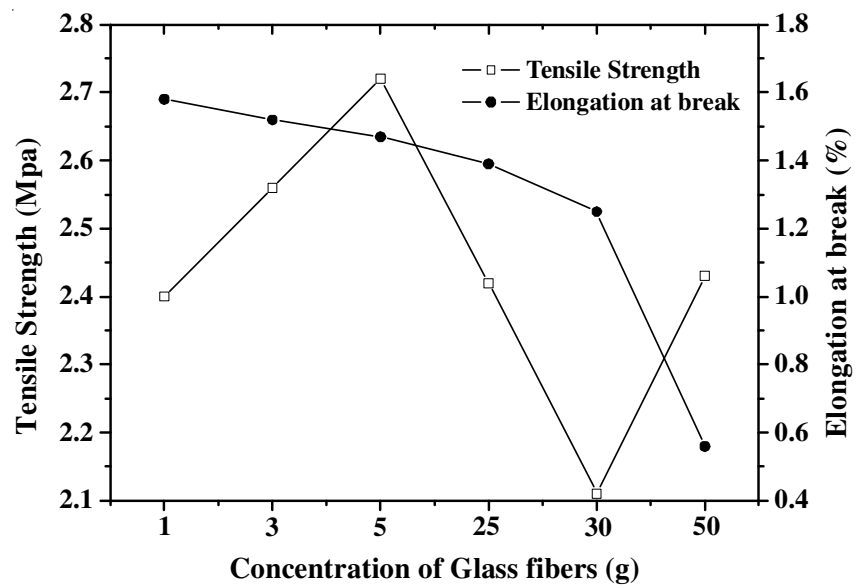

Fig. 2. Mechanical properties of glass fibers reinforced scrap rubber composites under different concentration of glass fibers. (length (L)/diameter (D) of glass fiber is 4:1)

The effect of different length (L)/diameter (D) of glass fibers on the damping properties of the composites were also studied. Fig. 3 shows the damping properties of glass fibers reinforced scrap rubber composites using different L/D of glass fibers. The damping properties of all the composites increased with the increase of the frequency. After the frequency increased 
to $200 \mathrm{~Hz}$, the dissipation factor became saturation and would not increase any more. When using glass fibers with $\mathrm{L} / \mathrm{D}=2$ : 1 , the dissipation factor of the composites is relative low value of 0.192 . However, the dissipation factor increased gradually with the increase of L/D. When we used the glass fibers with $\mathrm{L} / \mathrm{D}=4: 1$, the dissipation factor of the corresponding composite reached the maximum value of 0.314 . But if we increase the L/D of glass fibers than $4: 1$, the damping properties would decrease rapidly.

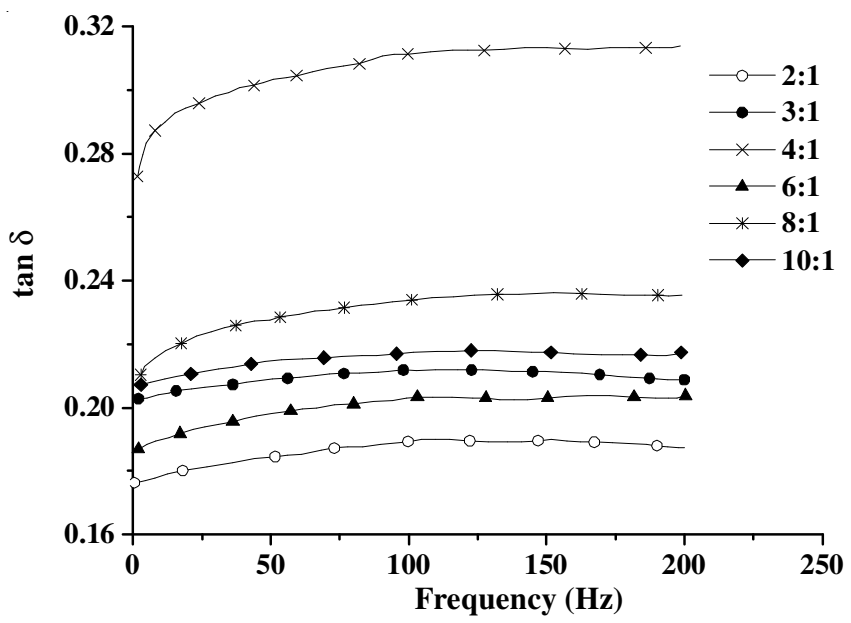

Fig. 3. Damping properties of glass fibers reinforced scrap rubber composites using different length (L)/diameter (D) of glass fibers

Fig. 4 shows the mechanical properties of glass fibers reinforced scrap rubber composites using different $\mathrm{L} / \mathrm{D}$ of glass fibers. The tensile strength first decreased slowly with the increase of the ratio of $L / D$. When the ratio of $L / D=4: 1$, the curves appeared an inflexion and the tensile strength then decreased rapidly. After increase the value to the ratio of L/D $=6: 1$, the tensile strength would increase with the increase of the ratio of L/D. However, the elongation at the break of the composites first increased with the increase of ration of $\mathrm{L} / \mathrm{D}$ and then decreased rapidly at the inflexion of $\mathrm{L} / \mathrm{D}=4: 1$. It would increased again after the ratio of $L / D=6: 1$. From the Fig. 4, the maximum of elongation at the break was measured to be about 1.25 at the ratio of $\mathrm{L} / \mathrm{D}=4: 1$. From above studies, it is obvious that the $\mathrm{L} / \mathrm{D}=4: 1$ of glass fibers is an optimized value for keeping both damping and mechanical properties of the composites.

The interface topography of glass fibers reinforced scrap rubber composites was studied by scanning electron microscope (SEM). Fig. 5 shows the SEM images of interface topography of the composites with different concentration of glass fibers. The arrangement chaos of fibers became more and more larger with the increase of concentration of glass fibers (Fig. 5). This would form more friction sites at the interface when the composite samples were forced. Therefore, the more energy was dissipated or transformed to get more higher damping property. However, mixing more glass fibers in the scrap rubber matrix, especially over the concentration of $30 \mathrm{~g}$, the pull-out phenomena of fibers became more serious (Fig. 5). This was the reason that the damping properties of composites decreased when the concentration of glass fibers was increased to $30 \mathrm{~g}$.

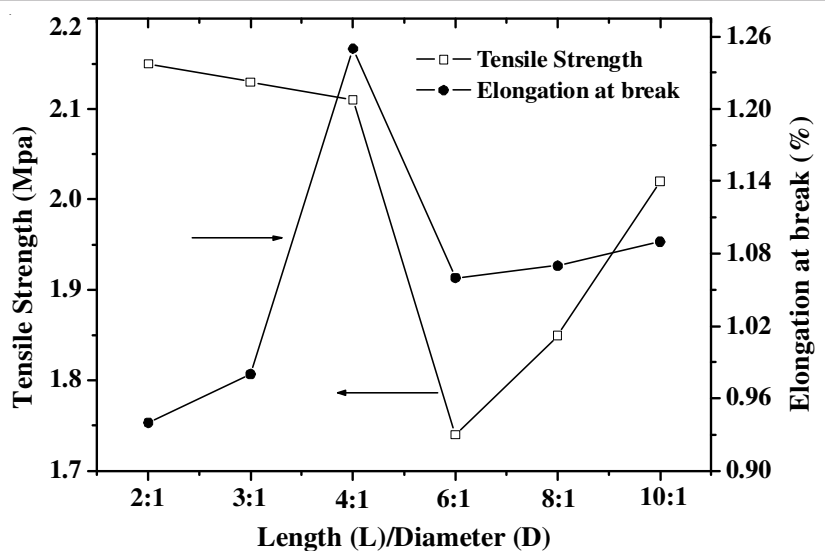

Fig. 4. Mechanical properties of glass fiber reinforced scrap rubber composites using different length (L)/diameter (D) of glass fibers

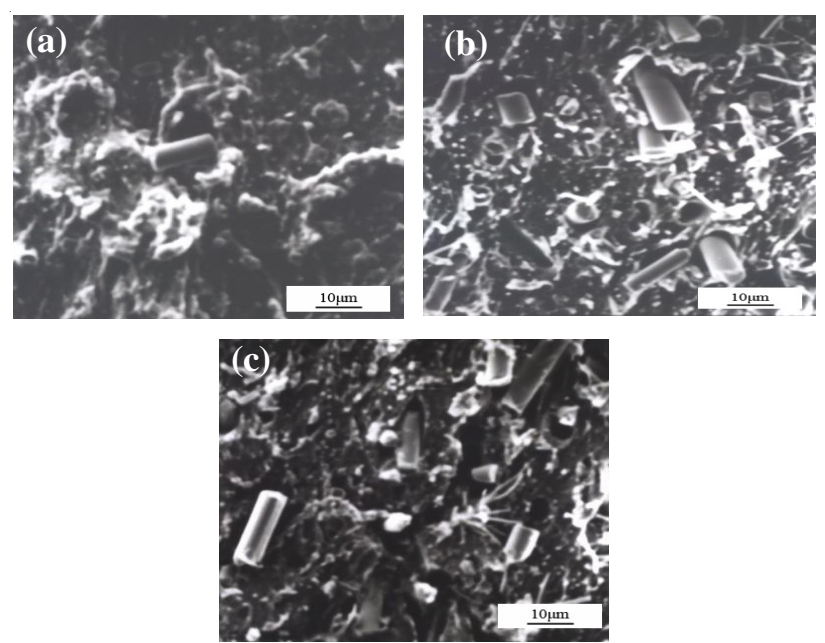

Fig. 5. SEM images of interface topography of the composites with different concentration of glass fibers with the $\mathrm{L} / \mathrm{D}=4: 1$ : (a) $1 \mathrm{~g}$, (b) $30 \mathrm{~g}$, (c) $50 \mathrm{~g}$

Fig. 6 shows the SEM images of interface topography of the composites with different L/D of glass fibers. The glass fibers were not easy to be destroyed with the increase of the L/D (Fig. 6). After the L/D of the glass fibers reaching a critical value (here is $4: 1$ ), the fibers would cumber the movement of scrap rubber, further to influence the energy dissipation or transformation. This was also the reason that the glass fibers with $L / D=4: 1$ is best reinforcement for scrap rubber damping composites.

\section{Conclusion}

A simple and efficient method to prepare glass fibers reinforced scrap rubber composites by just mixing has been developed. The effect of the concentration and length (L)/ diameter (D) on the damping and mechanical properties of the composite materials was studied in details. Combination with the damping and mechanical performances, the optimization values of the concentration and L/D were determined to be $30 \mathrm{~g}$ and 4:1. The interface topography was also studied by SEM to explore the microstructure and damping mechanism of the composites. The simple method can also be applied in environment protection, materials science and engineering and so on, especially for recycle the waste rubber powder to prepare high value damping materials. 



Fig. 6. SEM images of interface topography of the composites with different $\mathrm{L} / \mathrm{D}$ of glass fibers with the concentration of $30 \mathrm{~g}$ : (a) 2:1, (b) $4: 1$, (c) $10: 1$

\section{ACKNOWLEDGEMENTS}

The work was financially supported by the Natural Science Foundation of Jiangxi Province (CA200701131) and the National Natural Science Foundation of China(10962006).

\section{REFERENCES}

1. T. Amari, N.J. Themelis and I.K. Wernick, Resour. Policy, 25, 179 (1999).

2. B. Adhikari, D. De and S. Maiti, Prog. Polym. Sci., 25, 909 (2000).
3. W. Yang, W.J. Sun, W. Chu, C.F. Jiang and J. Wen, Chinese Chem. Lett., 23, 363 (2012).

4. D. Ray, S. Sengupta, S.P. Sengupta, A.K. Mohanty and M. Misra, Macromol. Mater. Eng., 292, 1075 (2007).

5. A. Pietak, S. Korte, E. Tan, A. Downard and M.P. Staiger, Appl. Surf. Sci., 253, 3627 (2007).

6. S. Panthapulakkal and M. Sain, J. Comp. Mater., 41, 1871 (2007).

7. K. John and S.V. Naidu, J. Reinf. Plast. Comp., 26, 373 (2007).

8. M.S. Sreekala, S. Thomas and G. Groeninckx, Polym. Compos., 26, 388 (2005)

9. L.A. Pothan, P. Potschke, R. Habler and S. Thomas, J. Comp. Mater, 39, 1007 (2005).

10. L.U. Devi, S.S. Bhagawan and S. Thomas, Polym. Compos., 31, 956 (2010).

11. H. Anuar, S.H. Ahmad, R. Rasid, A. Ahmad and W.N.W. Busu, J. Appl. Polym. Sci., 107, 4043 (2008).

12. S. Mandal and S. Alam, J. Appl. Polym. Sci., 125, E382 (2012).

13. D. Ratna, N.R. Manoj, L. Chandrasekhar and B.C. Chakraborty, Polym. Adv. Technol., 15, 583 (2004).

14. C. Su, P. He, R. Yan, C.B. Zhao and C. Zhang, Polym. Compos., 33, 860 (2012).

15. X.G. Diao, A.Y. Takeuchi, F. Garcia, R.B. Scorzelli and H.R. Rechenberg, J. Appl. Phys., 85, 4485 (1999).

16. J.M. Berthelot and Y. Sefrani, Compos. Sci. Technol., 64, 1261 (2004).

17. A. Zanchet, L.N. Carli, M. Giovanela, R.N. Brandalise and J.S. Crespo, Mater. Design, 39, 437 (2012).

18. M. Naghipour, F. Taheri and G.P. Zou, J. Struct. Eng., 131, 1044 (2005).

19. S. Houshyar, R.A. Shanks and A. Hodzic, J. Appl. Polym. Sci., 96, 2260 (2005).

20. C. Kyriazoglou and F.J. Guild, Compos. Part A, 36, 367 (2005).

21. H. Kishi, M. Kuwata, S. Matsuda, T. Asami and A. Murakami, Compos. Sci. Technol., 64, 2517 (2004). 